\title{
Valuation of Derivatives on the Cost Variables of the Shipping Market
}

\author{
Christos E. Kountzakis \\ Department of Statistics and Actuarial-Financial Mathematics, University of the Aegean, Mytilene, Greece \\ Email: chr_koun@aegean.gr
}

How to cite this paper: Kountzakis, C.E. (2017) Valuation of Derivatives on the Cost Variables of the Shipping Market. Journal of Mathematical Finance, 7, 513-517. https://doi.org/10.4236/jmf.2017.72027

Received: March 14, 2016

Accepted: May 28, 2017

Published: May 31, 2017

Copyright $\odot 2017$ by author and Scientific Research Publishing Inc. This work is licensed under the Creative Commons Attribution International License (CC BY 4.0).

http://creativecommons.org/licenses/by/4.0/

\begin{abstract}
In this paper, we present stochastic differential equations related to the cost variables of the shipping market. These SDEs arise under the addition of stochastic terms on the deterministic differential equations concerning the same variables. The financial interest arises from the fact that these SDEs may be used for the valuation of derivatives on these variables, such as futures, options, and others.
\end{abstract}

\section{Keywords}

Transport Costs Per Unit of Cargo Turnover, Deadweight, Optimum Speed

\section{Variables Which May Be Taken as Primary in Shipping Markets}

It is obvious that ship-owners, design the ships in a way that either minimizes the costs or maximizes the earnings arising from it. The relation between the design of a ship and the costs or the earnings is mentioned in Hughes-in [1], Veenstra and Ludemaz-in [2] and in Stopford-in [3]. In the first reference what is mentioned is that ship-owners consider these costs as constant and they are interested in the evolution of the earnings arising from a ship. In the second reference, the authors examine a relation between the technical characteristics of the ship and the earnings. Finally, in the third reference, cost and revenue variables related to a ship are separated, according to the impact of them. From Chen-in [4], we take the following relations:

$$
a_{t}=\frac{S}{Q_{m}},
$$

where $a_{t}$ denotes the transport costs per unit of cargo turnover, $S$ denotes the transport costs per year and $Q_{m}$ denotes the cargo turnover per year. 


$$
Q_{m}=\frac{\left(a_{1}+a_{2}\right) D W \cdot T \cdot L}{\frac{2}{24 V_{s}}+\frac{2\left(a_{1}+a_{2}\right) D W}{M_{c}}+t_{p_{2}}+t_{3}},
$$

where $a_{1}, a_{2}$ denote the utilization of ship's deadweight capacity for inbound and outbound voyages, respectively, $Q_{m}$ denotes the cargo turnover per year, $D W$ denotes the deadweight of the ship, $T$ denotes the service days per year, $L$ denotes indicates the voyage distance, and $M_{c}$ denotes the average cargo handling rate at port. Also, $t_{s 1}$ denotes the time sailing at a service speed for a round voyage, $t_{s 2}$ denotes the time of canal transit for a round voyage, $t_{p 1}$ denotes the time for cargo loading and discharging for a round voyage, $t_{p_{2}}$ denotes the turn time for a round voyage, and finally the time $t_{3}$ denotes the extra time at sea and in port for a round voyage. In Chen-in [4], differentiation with respect to $V_{s}$ gives

$$
\frac{\mathrm{d} Q_{m}}{Q_{m}}=\frac{t_{s l}}{t} \frac{\mathrm{d} V_{s}}{V_{s}},
$$

which implies

$$
\frac{\mathrm{d} a_{t}}{a_{t}}=\frac{\mathrm{d} S}{S}-\frac{\mathrm{d} Q_{m}}{Q_{m}}=\frac{\mathrm{d} S}{S}-\frac{t_{s 1}}{t} \frac{\mathrm{d} V_{s}}{V_{s}} .
$$

Also, in Chen (2011), differentiation of (1), with respect to $D W$ implies

$$
\frac{\mathrm{d} Q_{m}}{Q_{m}}=\left(1-\frac{t_{p 1}}{t}\right) \frac{\mathrm{d} D W}{D W},
$$

which leads to

$$
\frac{\mathrm{d} a_{t}}{a_{t}}=\frac{\mathrm{d} S}{S}-\left(1-\frac{t_{p 1}}{t}\right) \frac{\mathrm{d} D W}{D W} .
$$

\section{Financial Models and Derivatives}

It is obvious that $a_{t}, D W, Q_{m}, S, V_{s}$ are stochastic, namely they are subject to change during the service time-period $\tau \in[0, T]$, due to a variety of unknown factors. We suppose that each of these variables are subject to change, according to an Itô process across the service-time period:

$$
\begin{aligned}
& \frac{\mathrm{d} V_{s, \tau}}{V_{s, \tau}}=a\left(\tau, V_{s, \tau}\right) \mathrm{d} \tau+\sigma\left(\tau, V_{s, \tau}\right) \mathrm{d} B_{\tau}^{1}, \\
& \frac{\mathrm{d} S_{\tau}}{S_{\tau}}=b\left(\tau, S_{\tau}\right) \mathrm{d} \tau+f\left(\tau, S_{\tau}\right) \mathrm{d} B_{\tau}^{2}, \\
& \frac{\mathrm{d} D W_{\tau}}{D W_{\tau}}=h\left(\tau, D W_{\tau}\right) \mathrm{d} \tau+g\left(\tau, D W_{\tau}\right) \mathrm{d} B_{\tau}^{3} .
\end{aligned}
$$

By these stochastic differential equations, we make the above differential models more realistic, since we moreover assume that each of these variables has a value-but subject to a variability, because we may not forecast its exact value at a certain time-moment during the time-period $[0, T]$. Also, $\tau \in[0, T]$, and $B_{\tau}^{1}, B_{\tau}^{2}, B_{\tau}^{3}$ are usual 1-dimensional independent Brownian motions on $\mathbb{R}$, 
modelling the essential factors of uncertainty. If the models for the processes $V_{s, \tau}, S_{\tau}, D W_{\tau}, \tau \in[0, T]$ are captured, by the differential form we have above we take:

Proposition 1. The Stochastic Differential Equation for $V_{s, \tau}$ is

$$
\frac{\mathrm{d} Q_{\tau}}{Q_{\tau}}=\frac{t_{s l}}{t} a\left(\tau, V_{s, \tau}\right) \mathrm{d} \tau+\frac{t_{s 1}}{t} \sigma\left(\tau, V_{s, \tau}\right) \mathrm{d} B_{\tau}^{1}, \tau \in[0, T] .
$$

Proposition 2. The Stochastic Differential Equation for $a_{t, \tau}$ is

$$
\begin{aligned}
\frac{\mathrm{d} a_{t, \tau}}{a_{t, \tau}}= & \left(b\left(\tau, S_{\tau}\right)-\frac{t_{s l}}{t} a\left(\tau, V_{s, \tau}\right)\right) \mathrm{d} \tau \\
& +\left(f\left(\tau, S_{\tau}\right),-\frac{t_{s 1}}{t} \sigma\left(\tau, V_{s, \tau}\right)\right) \cdot\left(\mathrm{d} B_{t}^{1}, \mathrm{~d} B_{t}^{2}\right)^{\mathrm{T}}, \tau \in[0, T],
\end{aligned}
$$

where $\mathrm{T}$ denotes transpose matrix.

We also consider a banking account, namely an assetwhose evolution is

$$
\mathrm{d} B_{\tau}=r_{\tau} B_{\tau} \mathrm{d} \tau, B_{0}=1, \tau \in[0, T] .
$$

\section{Valuation}

We consider a European call-option on the transport cost per cargo for a certain ship at the end of the service-time $T$ at a strike-price $K$. The value of the underlying "asset"-which is the cost is now equal to $a_{t, T}$. The payoff of the call-option is equal to

$$
\left(a_{t, T}-K\right)^{+} .
$$

We also consider a call-option at the cargo $Q_{m, T}$ at the end of the service-time having a strike-price $K_{1}$. The payoff of the second option is

$$
\left(Q_{m, T}-K_{1}\right)^{+} \text {. }
$$

The difference of the two markets is that the market of $Q_{m}$ together with $B$ is complete, while the market of the cost $a_{t}$ together with $B$ is incomplete. Hence, the second call-option may be replicated by the classical spot-market theory, see in Musiela and Rutkowski-[5], 5.1.2: The unique equivalent martingale measure for the discounted cargo-market as a spot market is

$$
\frac{\mathrm{d} \mathbb{Q}}{\mathrm{d} \mathbb{P}}=\exp \left\{\frac{r_{\tau}-\frac{t_{s l}}{t} a\left(\tau, V_{s, \tau}\right)}{\frac{t_{s 1}}{t} \sigma\left(\tau, V_{s, \tau}\right)} B_{T}^{1}-\frac{1}{2}\left(\frac{r_{\tau}-\frac{t_{s l}}{t} a\left(\tau, V_{s, \tau}\right)}{\frac{t_{s 1}}{t} \sigma\left(\tau, V_{s, \tau}\right)}\right)^{2} T\right\}, \mathbb{P}-\text { a.s. }
$$

Under $\mathbb{Q}$, the price of $\mathrm{e}^{-r_{\tau}} Q_{m, \tau}=Q_{m, \tau}^{*}, \tau \in[0, T]$ is

$$
\mathrm{d} Q_{m, \tau}^{*}=\frac{t_{s 1}}{t} \sigma\left(\tau, V_{s, \tau}\right) Q_{m, \tau}^{*} \mathrm{~d} B_{\tau}^{*},
$$

where

$$
B_{\tau}^{*}=B_{\tau}^{1}-\frac{r_{\tau}-\frac{t_{s l}}{t} a\left(\tau, V_{s, \tau}\right)}{\frac{t_{s 1}}{t} \sigma\left(\tau, V_{s, \tau}\right)} \tau, \tau \in[0, T]
$$


is a Brownian motion. Hence,

$$
\pi_{\tau}\left(\left(Q_{m, T}-K_{1}\right)^{+}\right)=B_{\tau} \mathbb{E}_{\mathbb{Q}}\left(B_{T}^{-1}\left(Q_{m, T}-K_{1}\right)^{+} \mid \mathcal{F}_{\tau}\right), \tau \in[0, T],
$$

denotes the unique (martingale price) of the second call-option, where the $\mathcal{F}_{\tau}, \tau \in[0, T]$ denotes the filtration of the last Brownian motion $B^{*} . B_{T}^{-1}$ is the discount factor with respect to the time-period $T$.

On the other hand, for the valuation of the call-option

$$
\left(a_{t, T}-K\right)^{+}
$$

since the market of

$$
\begin{aligned}
\frac{\mathrm{d} a_{t, \tau}}{a_{t, \tau}}= & \left(b\left(\tau, S_{\tau}\right)-\frac{t_{s l}}{t} a\left(\tau, V_{s, \tau}\right)\right) \mathrm{d} \tau \\
& +\left(f\left(\tau, S_{\tau}\right),-\frac{t_{s 1}}{t} \sigma\left(\tau, V_{s, \tau}\right)\right) \cdot\left(\mathrm{d} B_{t}^{1}, \mathrm{~d} B_{t}^{2}\right)^{\mathrm{T}}, \tau \in[0, T],
\end{aligned}
$$

and

$$
\mathrm{d} B_{\tau}=r_{\tau} B_{\tau} \mathrm{d} \tau, B_{0}=1, \tau \in[0, T]
$$

is incomplete, in order to find the non-arbitrage prices for the $\left(a_{t, T}-K\right)^{+}$we formulate the process equation

$$
\begin{aligned}
& \left(f\left(\tau, S_{\tau}\right),-\frac{t_{s 1}}{t} \sigma\left(\tau, V_{s, \tau}\right)\right) \cdot\left(u_{\tau}^{1}, u_{\tau}^{2}\right)^{\mathrm{T}} \\
& =\left(b\left(\tau, S_{\tau}\right)-\frac{t_{s l}}{t} a\left(\tau, V_{s, \tau}\right)\right),
\end{aligned}
$$

which implies the existence of the scalar processes $u_{\tau}^{1}, u_{\tau}^{2}, \tau \in[0, T]$, such that

$$
f\left(\tau, S_{\tau}\right) u_{\tau}^{1}-\frac{t_{s 1}}{t} \sigma\left(\tau, V_{s, \tau}\right) u_{\tau}^{2}=b\left(\tau, S_{\tau}\right)-\frac{t_{s l}}{t} a\left(\tau, V_{s, \tau}\right), \tau \in[0, T]
$$

and consider a solution $u_{\tau}=\left(u_{\tau}^{1}, u_{\tau}^{2}\right), \tau \in[0, T]$, of the above stochastic equation (2) that satisfies the condition

$$
\mathbb{E}\left(\exp \left\{\frac{1}{2} \int_{0}^{T}\left\|u_{\tau}\right\|_{2}^{2} \mathrm{~d} \tau\right\}\right)<\infty .
$$

We also consider

$$
\frac{\mathrm{d} \mathbb{Q}_{u}}{\mathrm{~d} \mathbb{P}}=\exp \left\{-\int_{0}^{T} u_{\tau} \mathrm{d} B_{\tau}-\frac{1}{2} \int_{0}^{T}\left\|u_{\tau}\right\|_{2}^{2} \mathrm{~d} \tau\right\},
$$

and $\mathrm{d} B_{\tau}=\left(\mathrm{d} B_{\tau}^{1}, \mathrm{~d} B_{\tau}^{2}\right)^{\mathrm{T}}, \tau \in[0, T]$. Also, the process

$$
B_{\tau}^{*}=\int_{0}^{\tau} u_{s} \mathrm{~d} s+B_{\tau},
$$

is a $\mathbb{Q}_{u}$-Brownian, where $\int_{0}^{\tau} u_{s} \mathrm{~d} s$ denotes component-wise integration. Hence,

$$
\frac{\mathrm{d} a_{t, \tau}}{a_{t, \tau}}=\left(f\left(\tau, S_{\tau}\right),-\frac{t_{s 1}}{t} \sigma\left(\tau, V_{s, \tau}\right)\right) \mathrm{d} B_{\tau}^{*}, \tau \in[0, T],
$$

is a $\mathbb{Q}_{u}$-martingale (we assume that the filtration is considered to be the same) —is Øksendal in [6], Chapter 12. 
Uder the above considerations, the following Theorem is obvious:

Theorem 3. The non-arbitrage prices of the call-option are-at time period 0 :

$$
\left(\inf _{\mathbb{Q}_{u}} \mathbb{E}_{\mathbb{Q}_{u}} B_{T}^{-1}\left(\left(a_{t, T}-K\right)^{+}\right), \sup _{\mathbb{Q}_{u}} \mathbb{E}_{\mathbb{Q}_{u}} B_{T}^{-1}\left(\left(a_{t, T}-K\right)^{+}\right)\right) \text {, }
$$

where $B_{T}^{-1}$ is the discount factor with respect to the time-period $T$.

\section{Conclusion}

The conclusion of this brief paper is that we may discriminate the primary cost variables in the shipping market and the dependence of other variables of this market, by the formulation of Stochastic Differential Equations. These SDE imply the valuation of European options written on the primary variables.

\section{References}

[1] Hughes, C. (1996) Ship Performance. LLP, London.

[2] Veenstra, A.W. and Ludemaz, M.W. (2006) The Relationship between Design and Economic Performance of Ships. Maritime Policy and Management, 33, 159-171. https://doi.org/10.1080/03088830600612880

[3] Stopford, M. (2009) Maritime Economics. 3rd Edition, Routledge, London. https://doi.org/10.4324/9780203891742

[4] Chen, S. (2011) Modelling and Forecasting in the Dry Bulk Shipping Market. Ph.D. Dissertation, Technical University of Delft, The Netherlands.

[5] Musiela, M. and Rutkowski, M. (1998) Martingale Methods in Financial Modelling. 2nd Edition, Springer.

[6] Øksendal, B. (2003) Stochastic Differential Equations-An Introduction with Applications. Springer.

Submit or recommend next manuscript to SCIRP and we will provide best service for you:

Accepting pre-submission inquiries through Email, Facebook, LinkedIn, Twitter, etc. A wide selection of journals (inclusive of 9 subjects, more than 200 journals) Providing 24-hour high-quality service User-friendly online submission system Fair and swift peer-review system Efficient typesetting and proofreading procedure Display of the result of downloads and visits, as well as the number of cited articles Maximum dissemination of your research work

Submit your manuscript at: http://papersubmission.scirp.org/

Or contact jmf@scirp.org 